\title{
Protein degradation in mitochondria
}

\author{
M ichael Käser and Thomas L anger*
}

The biogenesis of mitochondria and the maintenance of mitochondrial functions depen ds on an auton omous proteolytic system in the organelle which is highly conserved throughout evolution. Components of this system include processing peptidases and AT P-depen dent proteases, as well as molecular chaperon eproteins and protein complexes with apparen tly regulatory functions. Whileprocessing peptidases mediatematuration of nuclear-encoded mitochondrial preproteins, quality control within various subcompartments of mitochondria is en su red by AT P-depen dent proteases which selectively remove non-assembled or misfolded polypeptides. M oreover, these proteases appear to control the activity- or steady-state levels of specific regulatory proteins and thereby en su re mitochon drial genome integrity, gene expression and protein assembly.

Key words: AAA proteases / L on proteases / mitochondria / prohibitins/ proteolysis

(C) 2000 Academic Press

\section{Introduction}

The selective degradation of proteins is essential for cellular homeostasis and allows its adaptation to altered environmental conditions. Similar to the turnover of cytosolic proteins, proteolysis of mitochondrial proteins can occur in the lysosomal compartment upon autophagy of the whole organelle.1 While this process is predominant under starvation conditions and results in the non-selective removal of mitochondrial proteins, processing or proteolysis of specific mitochondrial proteins is

From the Adolf-Butenandt-Institut für PhysiologischeChemie, L udwigM aximilians-Universität M ünchen, Goethestr. 33, 80336 M ünchen, Germany. E-mail: langer@bio.med.uni-muenchen.de

(C) 2000 A cademic Press

$1084-9521 / 00 / 030181+10 / \$ 35.00 / 0$

*Corresponding author. mediated by peptidases within mitochondria themselves. ${ }^{2,3}$ In general, these peptidases are highly conserved and, at least in most cases, appear to be ubiquitously present in mitochondria of eukaryotic cells (Figure 1). Mitochondrial peptidases can be divided into three groups: processing peptidases, oligopeptidases and ATP-dependent proteases. We will focus in this review on ATP-dependent proteases in mitochondria and only briefly summarize the current understanding on other peptidases which is described in a comprehensive manner elsewhere. ${ }^{4-9}$

\section{Mitochondrial processing peptidases}

The vast majority of mitochondrial proteins is nuclear encoded. The notion, that targeting to mitochondria and intramitochondrial sorting is ensured by $\mathrm{N}$-terminal presequences which are proteolytically cleaved off once proteins reach their final destination, provided first evidence for the existence of specific peptidases in mitochondria. Processing enzymes have been identified since then in various mitochondrial subcompartments (Table 1). Despite rather degenerate cleavage motifs, processing of mitochondrial preproteins occurs with high fidelity. It depends on structural information within the presequence and in regions adjacent to the cleavage site.

The mitochondrial processing peptidase (MPP) cleaves off $\mathrm{N}$-terminal mitochondrial targeting sequences of nuclear-encoded precursor proteins in

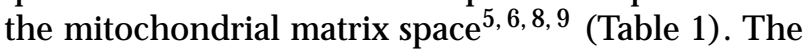
heterodimeric $\mathrm{Zn}^{2+}$-metallopeptidase consists of two subunits of about $50 \mathrm{kDa}$. Initial substrate recognition and binding is mediated by $\alpha$-MPP which presents presequences to the proteolytically active $\beta$-subunit for cleavage. 10,11 While many matrix and inner membrane proteins are released in their mature form from MPP, maturation of some matrix and intermembrane space proteins depends on a second processing step. The mitochondrial intermediate peptidase ( MIP) cleaves off $\mathrm{N}$-terminal octapeptides from some 


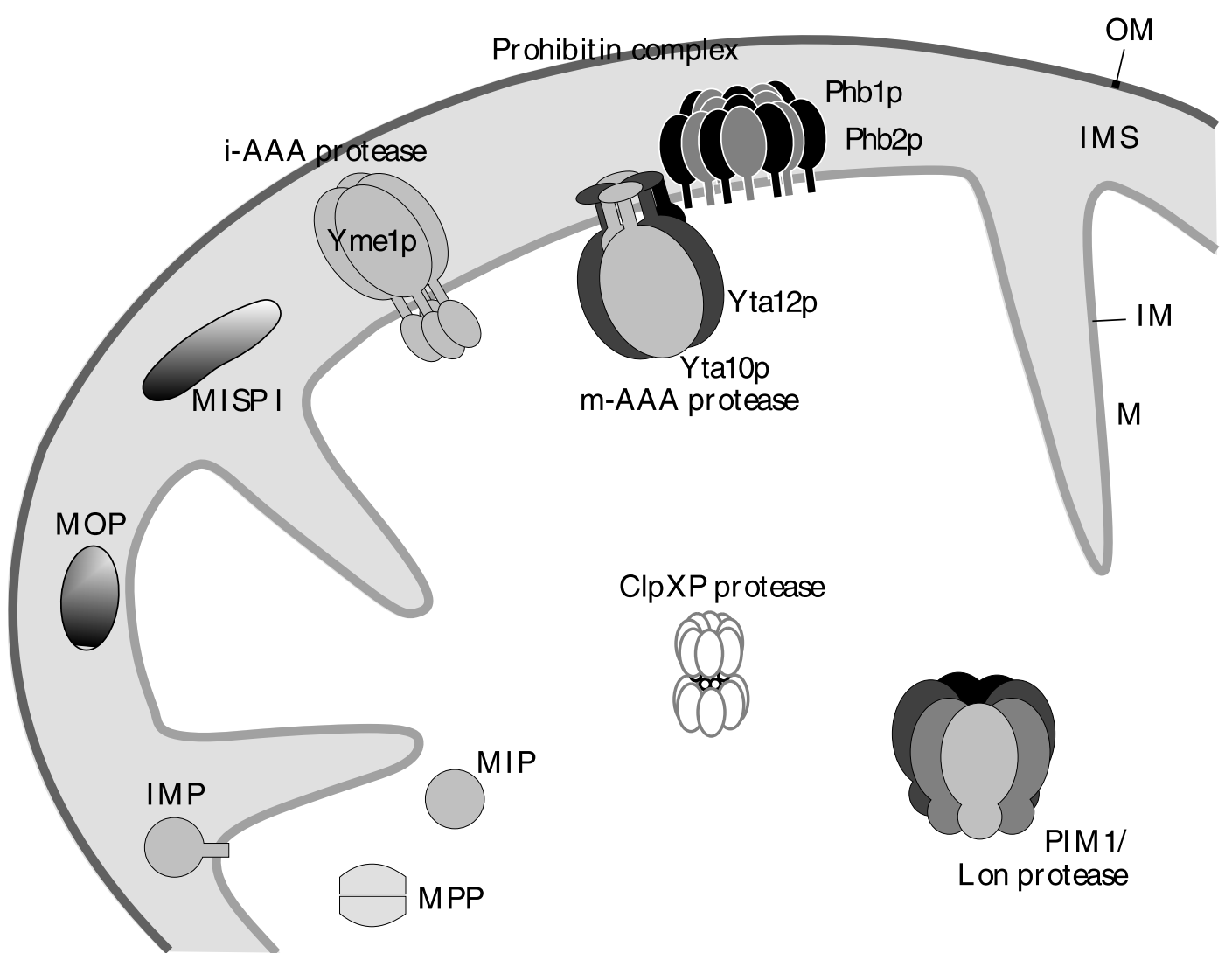

Figure 1. The proteolytic system of mitochondria. Maturation of nuclear-encoded preproteins is mediated by specific processing peptidases in various mitochondrial subcompartments: mitochondrial processing peptidase (MPP), mitochondrial intermediate peptidase (MIP), and inner membrane peptidase (IMP). ATP-dependent proteases degrade nonnative polypeptides and exert crucial regulatory functions in mitochondrial biogenesis: PIM 1/ Lon protease, CIpXP protease (only identified in mammalian mitochondria), $m$-AAA protease and $i$-AAA protease. An additional ATP-dependent protease has been identified in the intermembrane space of mammalian mitochondria (MISP I; mitochondrial intermembrane space protease I). ${ }^{88}$ The mitochondrial oligopeptidase MOP (termed yscD/ Prdlp in yeast) in the intermembrane space represents the only identified oligopeptidase in mitochondria. ${ }^{91,92}$ The prohibitin complex does not exhibit proteolytic activity but modulates proteolysis by the $m$-AAA protease. See text for details. OM, mitochondrial outer membrane: IMS, mitochondrial intermembrane space; IM , mitochondrial inner membrane; $M$, mitochondrial matrix.

matrix-localized proteins including iron-utilizing proteins and components of the electron transport chain, the tricarboxic cycle and the mitochondrial genetic machinery. $12-15$ The physiological function of processing by MIP, however, remains to be elucidated. Maturation of intermembrane space proteins with a bipartite presequence occurs by consecutive cleavage by MPP in the matrix and by the inner membrane protease (IMP) in the intermembrane space. 4,16,17 The latter protease is homologous to eubacterial and eukaryotic signal peptidases. ${ }^{18}$ It is composed of two related subunits with non-overlapping substrate specificities, Imp1p and Imp2p, both of which are an integral part of the inner membrane and expose their catalytic sites to the intermembrane space. ${ }^{19}$

\section{AT P-dependent proteases of mitochondria}

In contrast to limited proteolytic events mediated by processing peptidases, ATP-dependent proteases mediate the complete degradation of dispensable mitochondrial proteins. Several ATP-dependent proteases have been identified in different subcompartments of mitochondria (Table 2). They are all derived from bacterial ancestors and comprise highly conserved protein families in eukaryotic cells. ${ }^{2,3,20}$ Studies in the yeast Saccharomyces cerevisiae revealed a dual function of ATP-dependent proteases in mitochondria. On one hand, they constitute a quality control system and prevent the possibly deleterious 
accumulation of non-assembled and misfolded polypeptides in the organelle. On the other hand, the selective proteolysis of some mitochondrial proteins by ATP-dependent proteases appears to be crucial for mitochondrial biogenesis. Increasing evidence suggests that a loss of the latter activity explains severe phenotypes associated with mutations in ATP-dependent proteases in various organisms including man.

\section{Lon-like proteases in the matrix}

Lon-like proteases build up a conserved protein family with membersin eubacteria, archaebacteria and eukaryotic cells where they appear to be exclusively localized to the matrix space of mitochondria. ${ }^{21-24}$ Functional conservation between various members of this family has been demonstrated by complementation studies in yeast. ${ }^{25,26}$ Lon-like proteases form homooligomeric complexes. While the stoichiometry of Escherichia coli Lon protease is still a matter of debate, a heptameric stoichiometry has recently been described for the yeast homologue ${ }^{27}$ which is also termed PIM 1 protease. $^{21,22}$ The analysis of mitochondrial extracts provided first evidence for the existence of an even larger high molecular mass assembly in vivo. ${ }^{28}$

Several domains can be distinguished in subunits of Lon-like proteases. They harbour an ATPase domain characteristic of Walker-type P-loop ATPases which exhibits a tertiary fold similar to other ATP-dependent proteases. 29,30 ATP hydrolysis is indispensable for proteolysis whereas ATP binding was found to be required for oligomerization of yeast PIM 1 protease. ${ }^{28,31}$ A proteolytic domain containing the catalytically active serine residue is present at the C-terminus of the protease subunits. Mitochondrial Lon-like proteases contain an additional $\mathrm{N}$-terminal domain of unknown function which is absent in eubacterial homologues. As shown for PIM 1 protease in yeast, sorting to mitochondria is ensured by a targeting sequence and a pro-region at the $\mathrm{N}$-terminus. ${ }^{28}$ While the targeting sequence is cleaved off by MPP in the matrix, the pro-region is autocatalytically removed upon assembly of PIM 1 subunits.

Substrates of Lon-like proteases in mitochondria have only been identified in yeast and include various non-assembled polypeptides, such as $\beta$-MPP, subunits $\alpha, \beta$ and $\gamma$ of the $\mathrm{F}_{1} \mathrm{~F}_{0}$-ATP synthase and ribosomal proteins, ${ }^{20}$ as well as missorted and misfolded model proteins. $^{32}$ PIM 1 protease is thus part of a quality control system in the matrix preventing the accumulation of non-native polypeptides. Consistently, inclusion bodies containing most likely aggregated mitochondrial proteins have been observed in yeast mitochondria lacking PIM 1 protease. ${ }^{22}$ It is conceivable that the ATPase domain of Lon proteases exerts chaperone-like activity, promotes substrate unfolding and ensures the specificity of proteolysis, as such a role has been demonstrated for structurally related ATPase domain s of other ATP-dependent proteases. ${ }^{33}$ This activity, however, is apparently not sufficient to prevent the aggregation of substrate polypeptides, a prerequisite for their degradation by Lon-like proteases. This is achieved by the mitochondrial H sp70 system which was found to cooperate with PIM1 protease in the degradation of misfolded polypeptides in the matrix of mitochondria. ${ }^{32}$ The H sp70 system also promotes folding of newly imported proteins in the matrix and thus represents a checkpoint between folding and degradation of mitochondrial proteins. The fate of a polypeptide is thought to be determined by the kinetics of partitioning between an association with PIM 1 protease for proteolysis and binding to the $\mathrm{H}$ sp70 system for folding. 3,32

Inactivation of PIMI protease in yeast causes severe phenotypes which appear to reflect specific regulatory functions of the protease during mitochondrial biogenesis rather than the deleterious effect of non-native polypeptides accumulating in the absence of the protease. PIM 1 protease affects the expression of mitochondrially encoded respiratory chain subunits at multiple steps and is therefore required for cell growth on non-fermentable carbon sources (Figure 2) (see Reference 34 for a comprehensive review). Cells lacking PIM 1 protease accumulate extensive mutations in the mitochondrial DNA (mtDNA). ${ }^{21,22}$ The molecular basis of this phenotype is presently unclear, but the peculiar property of bacterial and human Lon proteases to bind single-stranded DNA in a site-specific manner suggests a direct role of Lon-like proteases in the mtDNA metabolism. ${ }^{35,36}$ Moreover, PIM1 protease controls the expression of two mitochondrial mosaic genes, $C O X 1$ and $C O B$, which encode the essential respiratory chain subunits Coxlp (subunit 1 of cytochrome $c$ oxidase) and Cob (cytochrome $b$ of the cytochrome $b_{1}$-complex). ${ }^{37}$ PIM 1-mediated proteolysis is required for the splicing of introns in both genes which code for RNA maturases. These enzymes are synthesized as fusion proteins with preceeding exons and activated by proteolytic removal of the exon-encoded moiety. ${ }^{38,} 39 \mathrm{It}$ is an attractive possibility that PIM 1 protease mediates this cleavage reaction. Alternatively, the protease may control the activity of 
Table 1. Processing peptidases of mitochondria

\begin{tabular}{|c|c|c|c|c|}
\hline Peptidase & Localization & Subunits & Proteolytic activity & Substrates \\
\hline $\begin{array}{l}\text { MPP (mitochondrial } \\
\text { processing } \\
\text { peptidase) }\end{array}$ & matrix & $\begin{array}{l}\alpha-M P P \\
\beta-M P P\end{array}$ & $\mathrm{Zn}^{2+}$-metallopeptidase & $\begin{array}{l}\text { - soluble matrix proteins } \\
\text { - IM proteins } \\
\text { - IMS proteins with bipartite } \\
\text { presequences }\end{array}$ \\
\hline $\begin{array}{l}\text { MIP (mitochondrial } \\
\text { intermediate } \\
\text { peptidase) }\end{array}$ & matrix & & metallopeptidase & $\begin{array}{l}\text { - iron-utilizing proteins } \\
\text { - respiratory chain subunits } \\
\text { - tricarboxic cycle enzymes } \\
\text { - components of the } \\
\text { mitochondrial genetic } \\
\text { machinery }\end{array}$ \\
\hline $\begin{array}{l}\text { IMP (inner } \\
\text { membrane } \\
\text { peptidase }\end{array}$ & $\begin{array}{l}\text { IM, } \\
\text { facing the IMS }\end{array}$ & $\begin{array}{l}\text { Implp } \\
\text { Imp2p }\end{array}$ & serine-peptidase & $\begin{array}{l}\text { - IM and IMS proteins with } \\
\text { bipartite presequences }\end{array}$ \\
\hline
\end{tabular}

regulatory proteins directly involved in pre-mRNA splicing. After transcript maturation, translation of COX 1 mRNA also dependson PIM 1 protease ${ }^{37}$ which thus exerts multiple functions in mitochondrial gene expression essential for the maintenance of the respiratory competence of the cell.

\section{Clp-like proteases in the matrix}

Proteases homologous to eubacterial CIp proteases have been identified in the matrix of mammalian mitochondria but are absent in lower eukaryotes such as yeast. ${ }^{37,40,41}$ Next to nothing, however, isknown about their physiological function. Clp-like proteases form hetero-oligomeric complexes with an interior chamber for proteolysis and are built up by AT Pase and proteolytic subunits. ${ }^{33,42}$ The ATPase subunits belong to the H sp100/ Clp family, ${ }^{43,44}$ members of which function both as chaperones and as subunits of bacterial Clp proteases. They unfold misfolded polypeptides allowing either their refolding by other chaperone systems or, if associated with proteolytic subunits, their degradation. Notably, though lacking proteolytic subunits, homologues of the ATPase subunits are present in the matrix of yeast mitochondria. Yeast $\mathrm{Hsp} 78$, a member of the CIpB subfamily of chaperones in the matrix, ${ }^{45}$ has apparently no proteolytic function but is required for mitochondrial thermotolerance. ${ }^{46} \mathrm{Ho}$ mologues of E. coli CIpX have been identified in mammals and yeast. While forming the AT Pase subunit of a Clp-like protease in mammalian mitochondria, ${ }^{41}$ it might act as a chaperone on its own in yeast lacking an apparent proteolytic partner. ${ }^{47}$

\section{AAA proteases in the mitochondrial inner membrane}

A large number of mitochondrial proteins are located in the inner membrane which is characterized by an extremely high protein content. ${ }^{48}$ Quality control of inner membrane proteins is ensured by two ATPdependent proteases, termed AAA proteases, which are an integral part of this membrane and exert a key function in the maintenance of its integrity. 49 They expose their catalytic sites to opposite membrane surfaces, the $m$ atrix and the intermembrane space side, and are accordingly termed $m$ - and $i$-AAA protease. O rthologues of both proteasesare seemingly present in mitochondria of all eukaryotic cells but are best studied in the yeast $S$. cerevisiae.

Mitochondrial AAA proteases belong to a highly conserved protein family with homologues also present in chloroplasts and eubacteria. ${ }^{49,50}$ They build up large complexes with a native molecular mass of approximately $1 \mathrm{MDa}$ in the mitochondrial inner membrane which are composed of identical or closely related subunits of 70-80 kDa. ${ }^{51,52}$ All subunits contain an ATPase domain, which is characteristic of the AAA superfamily of ATPases (for ATPases associated with a variety of cellular activities) $30,53,54$ and which has chaperone-like properties. ${ }^{55}$ A proteolytic domain with metallopeptidase activity is present at their C-terminus. AAA proteases degrade, in contrast to soluble ATP-dependent proteases, membraneembedded polypeptides if they are non-assembled or misfolded. Inactivation of AAA proteases causes severe defects in various organisms including neurodegeneration in humans, most likely reflecting regulatory functions of these proteases crucial for the biogenesis and homeostasis of mitochondria. 


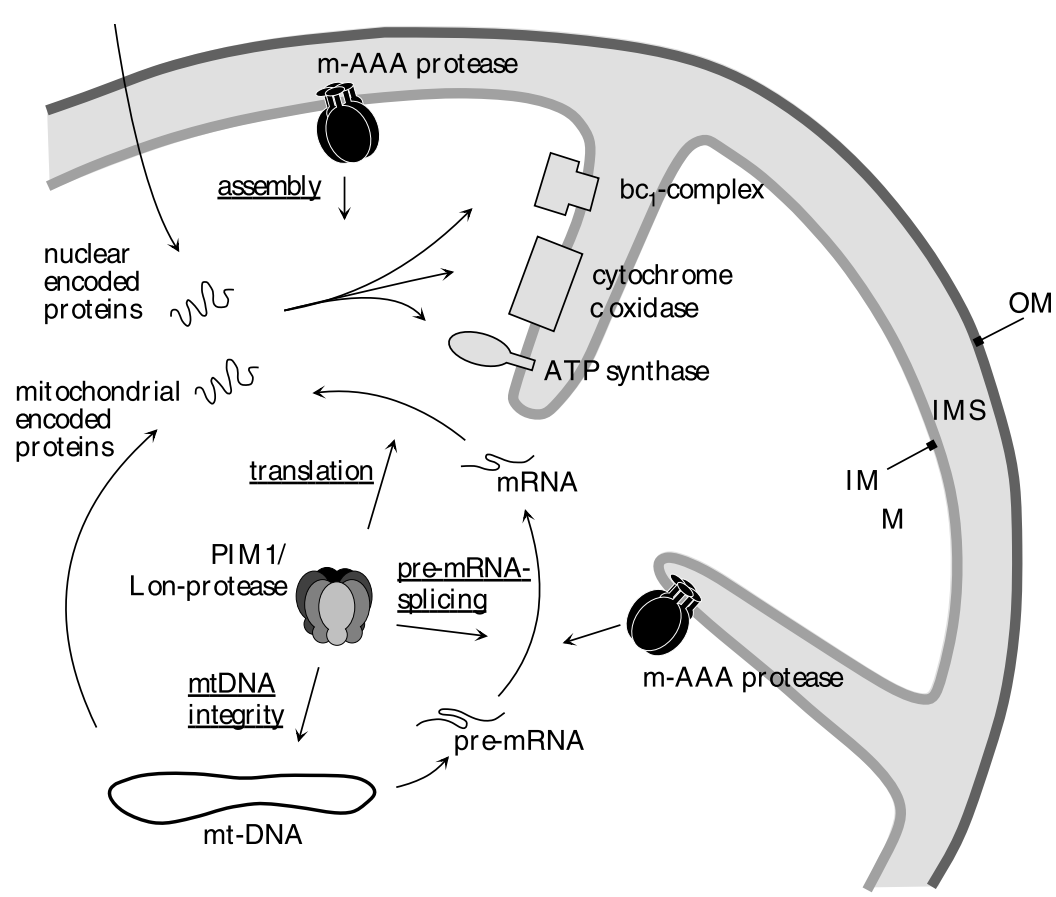

Figure 2. Roles of ATP-dependent proteasesin mitochondrial gene expression and protein assemblyin S. cerevisiae. Processes under the proteolytic control of ATP-dependent proteases are underlined. See text for details. OM, mitochondrial outer membrane; IMS, mitochondrial intermembrane space; IM, mitochondrial inner membrane; $M$, mitochondrial matrix.

\section{i-AAA protease}

The $i$-AAA protease in yeast appears to represent a homo-oligomeric complex composed of Ymelp subunits. ${ }^{52}$ Ymelp contains one transmembrane segment. An $\mathrm{N}$-terminal domain of approximately 170 amino acid residues is present in the matrix space while a large C-terminal domain with the catalytic sites is exposed to the intermembrane space. ${ }^{52}$ Point mutations in the proteolytic center of Ymelp or a deletion of the complete YME1 gene both result in identical pleiotropic defects in S. cerevisiae. ${ }^{56-58}$ Cells lose their respiratory competence at elevated temperature and accumulate mitochondria with a punctate, non-reticulated morphology. The latter phenotype has been suggested to result in an increased turnover of mitochondria in the vacuolar compartment. ${ }^{59}$ This scenario could provide an explanation for the increased rate of mEDNA escape which has originally lead to the identification of the YME1 gene. ${ }^{60}$ The molecular basis of various phenotypes associated with ymel mutations is presently not understood, but it appears likely that multiple proteolytic substrates of Ymelp exist. Consistently, each of the various phenotypes can be suppressed individually by different extragenic mutations. ${ }^{58,59,61,62}$ The only reported substrate of the $i$-AAA protease, however, is non-assembled subunit 2 of cytochrome $c$ oxidase $($ Cox $2 p), 57,63,64$ illustrating the quality control function of the protease in the inner membrane.

\section{m-AAA protease}

In S. cerevisiae, the $m$-AAA protease is composed of multiple copies of two homologous subunits, Yta10p (Afg3p) ${ }^{65,66}$ and Yta12p (Rcalp), ${ }^{67,68}$ which are closely related to each other and to the $i$-AAA protease subunit Ymelp. ${ }^{51}$ In contrast to Ymelp, Yta10p and Yta12p span the inner membrane twice. A small $\mathrm{N}$-terminal and a large $\mathrm{C}$-terminal domain harbouring the catalytic sites are exposed to the matrix. ${ }^{51}$ Mutational analysis of both proteins in yeast revealed first evidence for an overlapping but non-identical substrate specificity of Yta10p and Yta12p. ${ }^{52,69} \mathrm{~A}$ variety of substrate polypeptides has been identified including non-assembled subunits of respiratory chain complexes and of the $F_{1} F_{0}$-ATP synthase. ${ }^{51,70}$ All of these polypeptides are an integral part of the inner membrane but it is likely that the $m$-AAA protease is also capable of degrading proteins peripherally associated with the inner membrane. 
The pivotal role of the $m$-AAA protease of mitochondrial biogenesis is illustrated by strong phenotypes associated with mutations in Yta10p and Yta12p in yeast. The $m$-AAA protease is essential for the maintenance of oxidative phosphorylation. ${ }^{65,66,68,69}$ The expression of the mitochondrially encoded respiratory chain subunits Coxlp and Cob isunder the proteolytic control of the $m$-AAA protease. ${ }^{69}$ Impaired splicing of $C O X 1$ and $C O B$ introns encoding RNA maturases was observed in the cells lacking $m$-AAA protease (Figure 2). Similar to the matrix-localized PIM 1 protease, the $m$-AAA protease might be involved in the proteolytic activation of RNA maturases (see Reference 34 for a comprehensive review). In any case, the activity of two ATP-dependent proteases, the PIM 1 and the $m$ AAA protease, is required to ensure the expression of two mitochondrial mosaic genes coding for essential respiratory chain subunits. In addition to its role in mitochondrial gene expression, the $m$-AAA protease affects also the post-translational assembly of respiratory chain complexes and the $F_{1} F_{0}-$ ATP synthase. ${ }^{69,71}$ While these results establish crucial functions of the $m$ AAA protease in mitochondrial biogenesis, a detailed understanding of these processes awaits the identification of the target proteins of the protease.

Two orthologues of yeast $m$-AAA protease subunits have been identified in humans. ${ }^{72,73}$ Mutations in one of them, paraplegin, cause an autosomal recessive form of hereditary spastic paraplegia. ${ }^{72}$ Deficiencies in mitochondrial oxidative phosphorylation were observed in these cells, reminiscent of defects in yeast cells lacking Yta10p and Yta12p. These findings point to conserved functions in mitochondrial biogenesis of $m$-AAA proteases in yeast and mammals.

\section{Regulation of m-AAA protease activity by prohibitins}

The analysis of mitochondrial extracts by sizing chromatography in yeast revealed that the $m$-AAA protease is present in a supercomplex in the inner membrane which has a native molecular mass larger than $2 \mathrm{MDa}^{74}$ It associates with another membrane protein complex containing the prohibitin homologues Phb1p and Phb2p. While also an integral part of the inner membrane, Phb1p and Phb2p are largely exposed to the intermembrane space, i.e. to the opposite membrane surface as the $m$-AAA protease. ${ }^{74}$ The prohibitins do not represent novel subunits of the $m$-AAA protease as they are dispensable for its proteolytic activity. Rather, they appear to fulfill regulatory functions during proteolysis. An increased turnover of non-assembled inner membrane proteins by the $m$-AAA protease was observed in mitochondria lacking prohibitins suggesting a negative regulatory effect. ${ }^{74}$ Affecting the conformation of the $m$-AAA protease, the prohibitin complex may modulate its specific proteolytic activity. Alternatively, prohibitins may directly interact with substrate polypeptides and regulate their binding to the $m$-AAA protease. A similar function has been described for the E. coli proteins $\mathrm{HflK}$ and $\mathrm{HflC}$ which show sequence similarities to eukaryotic prohibitins and modulate the proteolytic activity of the E. coli AAA protease FtsH.$^{75-77}$ Thus, regulation of AAA proteases appears to be conserved and derived from an earlier common ancestor.

Prohibitin was originally identified in mammals due to its decreased expression in tumor cellsand itsability to negatively regulate cell proliferation. ${ }^{78,79} \mathrm{H}$ ighly conserved homologues appear to be ubiquitously present in all eukaryotic cells $s^{80}$ and have been implicated in diverse processes, such as the regulation of the cellular life $\operatorname{span}^{81}$ and the maintenance of mitochondrial morphology. ${ }^{82}$ It remains to be determined whether the various effects of prohibitins reflect their role in proteolysis or whether additional functions have to be envisioned. The solvent-exposed domain of prohibitins exhibit significant sequence similarity to stomatin-like proteinsand to the caveolaeassociated flotillins, raising the intriguing possibility that these proteinsare al so components of membraneassociated proteolytic complexes. ${ }^{83}$

\section{$Q$ uality control of mitochondrial proteins by AT P-dependent proteases}

The fidelity of proteolysis, i.e. the specificity of substrate recognition by mitochondrial ATP-dependent proteases is crucial to prevent cell damage. In the eukaryotic cytosol, polyubiquitination of proteolytic substrates ensures their targeting to the $26 \mathrm{~S}$ proteasome for proteolysis. ${ }^{84}$ There is, however, no evidence for the existence of a similar system within mitochondria nor have sequence motifs been identified which trigger the degradation of specific mitochondrial proteins. Rather, identified proteolytic substrates appear to be solely recognized due to their non-native conformation. Evidence for the importance of the folding state of mitochondrial proteinsfor proteolysis was provided by studies on the stability of hybrid proteins containing dihydrofolate reductase (DH FR). Destabilization of the DHFR domain at high temperature or by point mutations results in turnover of the hybrid proteins. This holds true for the proteolytic breakdown 
Table 2. ATP-dependent proteases in mitochondria of S. cerevisiae. See text for details. Proteolytic substrates identified represent exclusively non-assembled membrane proteins illustrating the quality control function of the proteases within mitochondria

\begin{tabular}{|c|c|c|c|c|}
\hline ATP-dependent protease & Localization & Subunits & Function & Substrates \\
\hline PIM 1/ Lon protease & matrix & Pimlp & $\begin{array}{l}\text { - mtDNA integrity } \\
\text { - COX1- and COB-pre- } \\
\text { mRNA splicing } \\
\text { - COX1 translation }\end{array}$ & $\begin{array}{l}\text { - Maslp } \\
\text { - } \alpha-\beta \text { - } \gamma \text {-subunit of the } \\
F_{1} \mathrm{~F}_{0} \text {-ATP synthase } \\
\text { - ribosomal proteins }\end{array}$ \\
\hline$m$-AAA protease & $\begin{array}{l}\text { IM, } \\
\text { facing the matrix }\end{array}$ & $\begin{array}{l}\text { Yta10p } \\
\text { (Afg3p) } \\
\text { Yta12p } \\
\text { Rcalp }\end{array}$ & $\begin{array}{l}\text { - COX1- and COB-pre- } \\
\text { mRNA splicing } \\
\text { - assembly of } b c_{1}- \\
\text { cytochrome } c \text { oxidase, } \\
\text { ATP synthase } \\
\text { complexes }\end{array}$ & $\begin{array}{l}\text { - Coxlp } \\
\text { - Cox3p } \\
\text { - Cyt } b_{2} \\
\text { - subunits 6, 8, } 9 \text { of the } \\
\mathrm{F}_{1} \mathrm{~F}_{0} \text {-ATP synthase }\end{array}$ \\
\hline$i$-AAA protease & $\begin{array}{l}\text { IM, } \\
\text { facing the IMS }\end{array}$ & Ymelp & $\begin{array}{l}\text { - maintenance of } \\
\text { respiratory competence } \\
\text { at high temperature } \\
\text { - mitochondrial } \\
\text { morphology }\end{array}$ & - Cox $2 p$ \\
\hline
\end{tabular}

of soluble proteins by PIM 1 protease in the matrix ${ }^{26}$ as well as for the turnover of integral membrane proteins, which expose an unfolded DH FR domain to the intermembrane space, by the $i$-AAA-protease. ${ }^{55}$

ATP-dependent proteases by themselves are capable of sensing the folding state of their substrates. The analysis of substrate binding to truncated versions of the $i$-AAA protease subunit Ymelp revealed a crucial function of its AAA domain, in particular of its $\mathrm{N}$-terminal part, for substrate binding. ${ }^{55}$ When expressed and purified from E. coli, the AAA-domain of Ymelp exerts chaperone-like properties: it binds specifically to non-native polypeptides and suppresses their aggregation. ${ }^{55}$ ATP-dependent conformational changes may result in unfolding of associated substrate polypeptides facilitating their subsequent degradation at the proteolytic site. Notably, all known ATP-dependent proteases are thought to have a conserved fold of ATPase domains suggesting mechanistic similarities. ${ }^{29,30}$ Indeed, a chaperone-like activity has been established for the ATPase subunits of both CIp proteases and the $26 \mathrm{~S}$ proteasome. ${ }^{85,86}$ E. coli CIpA was found to completely unfold a model substrate in vitro. ${ }^{87}$ Unfolding of misfolded substrate polypeptides may therefore be a common function of the ATPase domain of ATP-dependent proteases.

\section{Perspectives}

Although recent years have seen rapid progress in the understanding of the proteolytic system of mitochon- dria, many questions remain to be addressed. The mechanism of ATP-dependent proteolysis, in particular of membrane proteins, as well as the identification of authentic proteolytic substrates with regulatory functions in mitochondrial biogenesis will be a major focus of future studies. Moreover, additional proteolytic pathways may be established which, for instance, ensure the turnover of mitochondrial proteins in the outer membrane or intermembrane space. The existence of an ATP-dependent proteolytic activity in the mitochondrial intermembrane space in mammals has been reported. ${ }^{88}$ Increasing evidence links the cytosolic 26S-ubiquitin-proteasome system to mitochondria $^{58,89,90}$ but the molecular basis of these observations is still elusive. It appears that the mitochondrial proteolytic system still keeps a lot of its secrets.

\section{Acknowledgements}

We thank all our colleagues for stimulating discussions. Work in the author's laboratory was supported bygrantsfrom the Deutsche Forschungsgemeinschaft.

\section{References}

1. Takeshige K et al (1992) Autophagyin yeast demonstrated with proteinase-deficient mutants and conditions for induction. J Cell Biol 119:301-311

2. Rep M, Grivell LA (1996) The role of protein degradation in mitochondrial function and biogenesis. Curr Genet 30:367380 
3. Langer T, Neupert W (1996) Regulated protein degradation in mitochondria. Experientia 52:1069-1076

4. Pratje E, Esser K, Michaelis G (1994) The mitochondrial inner membrane peptidase, in Signal Peptidases (van H eijne G, ed.) pp. 105-112. R.G. Landes Comp, Austin

5. Brunner M, Neupert W (1995) Purification and characterization of the mitochondrial processing peptidase of N eurospora crassa. Methods Enzymol 248:717-728

6. Luciano P, Geli V (1996) The mitochondrial processing peptidase: function and specificity. Experientia 52:1077-1082

7. Isaya G, Kalousek F (1995) Mitochondrial intermediate peptidase. Methods Enzymol 248:556-567

8. Braun H-P, Schmitz U K (1997) The mitochondrial processing peptidase. Int J Biochem Cell Biol 29:1043-1045

9. Ito A (1999) Mitochondrial processing peptidase: multiplesite recognition of precursor proteins. Biochem Biophys Res Commun 265:611-616

10. Shimokata K et al (1997) Role of alpha-subunit of mitochondrial processing peptidase in substrate recognition. J Biol Chem 1998:25158-25163

11. Luciano P et al (1997) Functional cooperation of the mitochondrial processing peptidase subunits. J Mol Biol 272:213225

12. Kalousek F, Isaya G, Rosenberg LE (1992) Rat liver mitochondrial intermediate peptidase (MIP): purification and initial characterization. EMBO J 11:2803-2809

13. Isaya G, Miklos D, Rollins RA (1994) M IP1, a new yeast gene homologous to the rat mitochondrial intermediate peptidase gene, is required for oxidative metabolism in Saccharomyces cerevisiae. Mol Cell Biol 14:5603-5616

14. Branda SS, Isaya G (1995) Prediction and identification of new natural substrates of the yeast mitochondrial intermediate peptidase. J Biol Chem 270:27366-27373

15. Branda SS et al (1999) Yeast and human frataxin are processed to mature form in two sequential steps by the mitochondrial processing peptidase. J Biol Chem 274:22763-22769

16. Schneider A et al (1991) Inner membrane protease I, an enzyme mediating intramitochondrial protein sorting in yeast. EMBO J 10:247-254

17. Schneider A, Oppliger W, Jenö P (1994) Purified inner membrane protease I of yeast mitochondria is a heterodimer. J Biol Chem 269:8635-8638

18. Dalbey RE et al (1997) The chemistry and enzymology of the type I signal peptidase. Protein Sci 6:1129-1138

19. Nunnari J, Fox TD, Walter P (1993) A mitochondrial protease with two catalytic subunits of nonoverlapping specificities. Science 262:1997-2004

20. Suzuki CK et al (1997) ATP-dependent proteases that also chaperone protein biogenesis. Trends Biochem Sci 22:118123

21. Van Dyck L, Pearce DA, Sherman F (1994) PIM 1 encodes a mitochondrial ATP-dependent protease that is required for mitochondrial function in the yeast Saccharomyces cerevisiae. J Biol Chem 269:238-242

22. Suzuki CK et al (1994) Requirement for the yeast gene LON in intramitochondrial proteolysis and maintenance of respiration. Science 264:273-276

23. Wang $N$ et al (1993) A human mitochondrial ATP-dependent protease that is highly homologous to bacterial Lon protease. Proc Natl Acad Sci USA 90:11247-11251

24. Wang N et al (1994) Synthesis, processing and localization of human Lon protease. J Biol Chem 269:29308-29313

25. Barakat $S$ et al (1998) Maize containsa Lon protease gene that can partially complement a yeast pim1-deletion mutant. Plant Mol Biol 37:141-154
26. Teichmann U et al (1996) Substitution of PIM 1 protease in mitochondria by Escherichia coli Lon protease. J Biol Chem 271:10137-10142

27. Stahlberg $\mathrm{H}$ et al (1999) Mitochondrial Lon of Saccharomyces cerevisiae is a ring-shaped protease with seven flexible subunits. Proc Natl Acad Sci USA 96:6787-6790

28. Wagner I et al (1997) Autocatalytic processing of the ATPdependent PIM 1 protease: Crucial function of a pro-region for sorting to mitochondria. EMBO J 16:7317-7325

29. Lupas A et al (1997) Self-compartmentalizing proteases. Trends Biochem Sci 22:399-404

30. Neuwald AF et al (1999) AAA+: A class of chaperonelike ATPases associated with the assembly, operation, and disassembly of protein complexes. Genome Res 9:27-43

31. Van Dijl JM et al (1998) The ATPase and protease domains of yeast mitochondrial Lon: roles in proteolysis and respirationdependent growth. Proc Natl Acad Sci USA 95:10584-10589

32. Wagner I et al (1994) Molecular chaperones cooperate with PIM 1 protease in the degradation of misfolded proteins in mitochondria. EMBO J 13:5135-5145

33. Wickner S, Maurizi MR, Gottesman S (1999) Posttranslational quality control: folding, refolding, and degrading proteins. Science 286:1888-1893

34. Van Dyck L, Langer T (1999) ATP-dependent proteases controlling mitochondrial function in the yeast Saccharomyces cerevisiae. Cell Mol Life Sci 55:825-842

35. Fu GK, Smith MJ, Markovitz DM (1997) Bacterial protease L on is a site-specific DNA-binding protein. J Biol Chem 272:534538

36. Fu GK, Markovitz DM (1998) The human Lon protease binds to mitochondrial promoters in a single-stranded, site-specific, strand-specific manner. Biochemistry 37:1905-1909

37. Van Dyck L, N eupert W, Langer T (1998) The ATP-dependent PIM 1 protease is required for the expression of introncontaining genes in mitochondria. Genes Dev 12:1515-1524

38. Costazo MC, Fox TD (1990) Control of mitochondrial gene expression in Saccharomyces cerevisiae. Ann Rev Genet 24:91113

39. Grivell LA (1995) Nucleo-mitochondrial interactions in mitochondrial gene expression. Crit RevBiochem Mol Biol 30:121164

40. Bross P et al (1995) Human ClpP protease: CDNA sequence, tissue-specific expression and chromosomal assignment of the gene. FEBS Lett 377:249-252

41. De Sagarra MR et al (1999) Mitochondrial localization and oligomeric structure of $\mathrm{HClpP}$, the human homologue of $\mathrm{E}$. coli ClpP. J Mol Biol 292:819-825

42. Gottesman S, Maurizi MR, Wickner S (1997) Regulatory subunits of energy-dependent proteases. Cell 91:435-438

43. Schirmer EC et al (1996) H sp100/ Clp proteins: a common mechanism explains diverse functions. Trends Biochem Sci 21:289-296

44. Horwich AL (1995) Resurrection or destruction? Curr Biol 5:455-458

45. Leonhardt SA et al (1993) H sp78 encodes a yeast mitochondrial heat shock protein in the CIp family of ATP-dependent proteases. Mol Cell Biol 13:6304-6313

46. Schmitt M, Neupert W, Langer T (1996) The molecular chaperone H sp78 confers compartment-specific theromotolerance to mitochondria. J Cell Biol 134:1375-1386

47. Van Dyck $L$ et al (1998) Mcxip, a ClpX homologue in mitochondria of Saccharomyces cerevisiae. FEBS Lett 438:250254

48. Scheffler IE (1999) Mitochondria. Wiley \& Sons, New York

49. Langer $T$ (2000) AAA-Proteases-cellular machines for the 
degradation of membrane proteins. Trends Biochem Sci 25:247-257

50. Schumann W (1999) FtsH - a single chain charonin. FEMS Microbiol Rev 23:1-11

51. Arlt $\mathrm{H}$ et al (1996) The YTA10-12 complex, an AAA protease with chaperone-like activity in the inner membrane of mitochondria. Cell 85:875-885

52. Leonhard $\mathrm{K}$ et al (1996) AAA proteases with catalytic sites on opposite membrane surfaces comprise a proteolytic system for the ATP-dependent degradation of inner membrane proteins in mitochondria. EMBO J 15:4218-4229

53. Patel S, Latterich M (1998) The AAA team: related ATPases with diverse functions. Trends Cell Biol 8:65-71

54. Beyer A (1997) Sequence analysis of the AAA protein family. Protein Sci 6:2043-2058

55. Leonhard K et al (1999) Chaperone-like activity of the AAA domain of the yeast Ymel AAA protease. Nature 398:348-351

56. Thorsness PE, White KH, Fox TD (1993) Inactivation of YM E1 a member of the $\mathrm{ftsH}-\mathrm{SEC} 18-\mathrm{PAS1}-\mathrm{CDC} 48$ family of putative ATPase-encoding genes, causes increased escape of DNA from mitochondria in Saccharomyces cerevisiae. Mol Cell Biol 13:54185426

57. Weber ER, Hanekamp T, Thorsness PE (1996) Biochemical and functional analysis of the YME1 gene product, an ATP and zinc-dependent mitochondrial protease from $\mathrm{S}$. cerevisiae. Mol Biol Cell 7:307-317

58. Campbell CL et al (1994) Mitochondrial morphological and functional defects in yeast caused by ymel are suppressed by mutation of a $26 \mathrm{~S}$ protease subunit homologue. Mol Biol Cell 5:899-905

59. Campbell CL, Thorsness PE (1998) Escape of mitochondrial DNA to the nucleus in ymel yeast is mediated by vacuolardependent turnover of abnormal mitochondrial compartments. J Cell Sci 111:2455-2464

60. Thorsness PE, Fox TD (1990) Escape of DNA from mitochondria to the nucleus in Saccharomyces cerevisiae. Nature 346:376379

61. Weber ER et al (1995) Mutations in the mitochondrial ATP synthase gamma subunit suppress a slow-growth phenotype of ymelyeast lacking mitochondrial DNA. Genetics 140:435-442

62. Hanekamp T, Thorsness PE (1999) YNT 20, a bypass suppressor of ymel yme2, encodesa putative $3^{\prime}-5^{\prime}$ exonuclease localized in mitochondria of Saccharomyces cerevisiae. Curr Genet 34:438448

63. Pearce DA, Sherman F (1995) Degradation of cytochrome oxidase subunits in mutants of yeast lacking cytochrome $c$ and suppression of the degradation by mutation of ymel. J Biol Chem 270:1-4

64. Nakai T et al (1995) Multiple genes, including a member of the AAA family, are essential for the degradation of unassembled subunit 2 of cytochrome $c$ oxidase in yeast mitochondria. Mol Cell Biol 15:4441-4452

65. Guélin E, Rep M, Grivell LA ( 1994) Sequence of the AFG 3 gene encoding a new member of the FtsH / Ymel/ T ma subfamily of the AAA-protein family. Yeast 10:1389-1394

66. Tauer $\mathrm{R}$ et al (1994) Yta10p, a member of a novel ATPase family in yeast, is essential for mitochondrial function. FEBS Lett 353:197-200

67. Schnall $R$ et al (1994) Identification of a set of yeast genes coding for a novel family of putative ATPases with high similarity to consitutents of the $26 \mathrm{~S}$ protease complex. Yeast 10:1141-1155

68. Tzagoloff A et al (1994) A new member of a family of ATPases is essential for assembly of mitochondrial respiratory chain and ATP synthetase complexes in Saccharomyces cerevisiae. J Biol
Chem 269:26144-26151

69. Arlt $\mathrm{H}$ et al (1998) The formation of respiratory chain complexes in mitochondria is under the proteolytic control of the $m$-AAA protease. EMBO J 17:4837-4847

70. Guélin E, Rep M, Grivell LA (1996) Afg3p, a mitochondrial ATP-dependent metalloprotease, is involved in the degradation of mitochondrially-encoded $\mathrm{Cox} 1, \mathrm{Cox} 3, \mathrm{Cob}, \mathrm{Su} 6, \mathrm{Su} 8$ and Su9 subunits of the inner membrane complexes III, IV and V. FEBS Lett 381:42-46

71. Paul MF, Tzagoloff A (1995) Mutations in RCA1 and AFG3 inhibits $F_{1}$-ATPase assembly in Saccharomyces cerevisiae. FEBS Lett 373:66-70

72. Casari G et al (1998) Spastic paraplegia and OXPHOS impairment caused by mutations in paraplegin, a nuclearencoded mitochondrial metalloprotease. Cell 93:973-983

73. Banfi S et al (1999) Identification and characterization of AFG3L 2, a novel paraplegin-related gene. Genomics 59:51-58

74. Steglich G, Neupert W, Langer T (1999) Prohibitins regulate membrane protein degradation by the $m$-AAA protease in mitochondria. Mol Cell Biol 19:3435-3442

75. Kihara A, Akiyama $Y$, Ito K (1996) A protease complex in the Escherichia coli plasma membrane: $\mathrm{HflKC}$ ( $\mathrm{HflA}$ ) forms a complex with FtsH ( $\mathrm{HflB}$ ), regulating its proteolytic activity against SecY. EMBO J 15:6122-6131

76. Kihara A, Akiyama Y, I to K (1997) H ost regulation of Iysogenic decision in bacteriophage $\lambda$ : Transmembrane modulation of FtsH ( $\mathrm{HflB})$, the cll degrading protease, by $\mathrm{H}$ flKC ( $\mathrm{HflA})$. Proc Natl Acad Sci USA 94:5544-5549

77. Kihara A, Akiyama Y, I to K (1998) Different pathways for protein degradation by the FtsH/ H flKC membrane-embedded protease complex: an implication from the interference by a mutant form of a new substrate protein, YccA. J Mol Biol 279:175-188

78. McClung JK et al (1989) Isolation of a CDNA that hybrid selects antiproliferative mRNA from rat liver. Biochem Res Com 164:1316-1322

79. Nuel MJ et al (1991) Prohibitin, an evolutionary conserved intracellular protein that blocks DNA synthesis in normal fibroblasts and HeLa cells. Mol Cell Biol 11:1372-1381

80. McClungJK, JupeER, LiuXT, Dell'O rco RT (1995) Prohibitin: potential role in senescence, development, and tumor suppression. Exp Gerontol 30:99-124

81. Coates PJ et al (1997) The prohibitin family of mitochondrial proteins regulate replicative lifespan. Curr Biol 7:R607-R610

82. Berger KH, Yaffe MP (1998) Prohibitin family members interact genetically with mitochondrial inheritance components in Saccharomyces cerevisiae. Mol Cell Biol 18:4043-4052

83. Tavernarakis N, Driscoll M, Kyrpides NC (1999) The SPFH domain: implicated in regulating targeted protein turnover in stomatins and other membrane-associated proteins. Trends Biochem Sci 24:425-427

84. Laney JD, Hochstrasser M (1999) Substrate targeting to the ubiquitin system. Cell 97:427-430

85. Wickner Setal (1994) A molecular chaperone, ClpA, functions like DnaK and DnaJ. Proc Natl Acad Sci USA 91:12218-12222

86. Braun $B C$ et al (1999) The base of the proteasome regulatory particle exhibits chaperone-like activity. Nat Cell Biol 1:221226

87. Weber-Ban EU et al (1999) Global unfolding of a substrate protein by the H sp100 chaperone CIpA. Nature 401:90-93

88. Sitte N, Dubiel W, Kloetzel PM (1998) Evidence for a novel ATP-dependent protease from the rat liver mitochondrial intermembrane space: purification and characterisation. J Biochem 123:408-415

89. Fisk HA, Yaffe MP (1999) A role for ubiquitination in 
mitochondrial inheritance in Saccharomyces cerevisiae. J Cell Biol 145:1199-1208

90. Rinaldi $T$ et al (1998) A mutation in a novel yeast proteasomal gene, RPN11/ MPR1, produces a cell cycle arrest, overreplication of nuclear and mitochondrial DNA and an altered mitochondrial morphology. Mol Biol Cell 9:2917-2931

91. Serizawa A, Dando PM, Barrett AJ (1995) Characterization of a mitochondrial metallopeptidase reveals neurolysin as a homologue of thimet oligopeptidase. J Biol Chem 270:20922098

92. Büchler M, Tisljar U, Wolf DH (1994) Proteinase yscD (oligopeptidase $y s C D$ ). Structure, function and relationship of the yeast enzyme with mammalian thimet oligopeptidase (metalloendopeptidase, EP 24.15). Eur J Biochem 219:627639 